\title{
Prediction of paravalvular leakage after transcatheter aortic valve implantation
}

\author{
Luigi F. M. Di Martino' ${ }^{1}$ Wim B. Vletter ${ }^{2} \cdot$ Ben $_{\text {Ren }^{2}} \cdot$ Carl Schultz $^{2}$. \\ Nicolas M. Van Mieghem ${ }^{2}$ Osama I. I. Soliman ${ }^{2,3} \cdot$ Matteo Di Biase $^{1}$ • \\ Peter P. de Jaegere ${ }^{2} \cdot$ Marcel L. Geleijnse ${ }^{2}$
}

Received: 21 March 2015 / Accepted: 6 July 2015/Published online: 18 July 2015

(C) The Author(s) 2015. This article is published with open access at Springerlink.com

\begin{abstract}
Significant paravalvular leakage (PVL) after transcatheter aortic valve implantation (TAVI) is related to patient mortality. Predicting the development of PVL has focused on computed tomography (CT) derived variables but literature targeting CoreValve devices is limited, controversial, and did not make use of standardized echocardiographic methods. The study included 164 consecutive patients with severe aortic stenosis that underwent TAVI with a Medtronic CoreValve system $\odot$, with available preTAVI CT and pre-discharge transthoracic echocardiography. The predictive value for significant PVL of the CTderived Agatston score, aortic annulus size and eccentricity, and "cover index" was assessed, according to both echocardiographic Valve Academic Research Consortium (VARC) criteria and angiographic Sellers criteria. Univariate predictors for more than mild PVL were the maximal diameter of the aortic annulus size (for both angiographic and echocardiographic assessment of PVL), cover index (for echocardiographic assessment of PVL only), and Agatston score (for both angiographic and echocardiographic assessment of PVL). The aortic annulus eccentricity index was not predicting PVL. At multivariate
\end{abstract}

Osama I. I. Soliman

o.soliman@erasmusmc.nl

Marcel L. Geleijnse

m.geleijnse@erasmusmc.nl

1 From the Department of Cardiology, Ospedali Riuniti, Università degli studi di Foggia, Foggia, Italy

2 From the Department of Cardiology, Erasmus University Medical Center, Thoraxcenter, Ba304, 's-Gravendijkwal 230, 3015 CE Rotterdam, The Netherlands

3 From the Cardialysis Cardiovascular Core Laboratory, Rotterdam, The Netherlands analysis, Agatston score was the only independent predictor for both angiographic and echocardiographic assessment of PVL. Agatston score is the only independent predictor of PVL regardless of the used imaging technique for the definition of PVL.

Keywords Aortic valve · Transcatheter - Computed tomography $\cdot$ Echocardiography $\cdot$ Paravalvular leakage . TAVI

\section{Introduction}

Paravalvular aortic leakage (PVL) after transcatheter aortic valve implantation (TAVI) is a complication with potentially severe consequences [1-6]. The main focus in predicting the development of PVL has been on computed tomography (CT) derived variables such as calcium quantification with the Agatston score, aortic annulus size and eccentricity, and indexes relating the annulus dimensions to prosthesis size like the "cover index" [3]. However, prediction of PVL may be different for the various percutaneous valves, since the CoreValve Revalving System $\left(\right.$ is self-expandable while the Edwards SAPIEN ${ }^{\mathrm{TM}}$ prosthesis is a balloon-expandable one. In particular, in a self-expandable prosthesis, calcified native valves may pose resistance to deployment, resulting in an ellipsoidshaped stent and a higher incidence of PVL. Indeed, Agatston score was predictive for PVL in all published CoreValve specific studies [7-9]. However, literature focusing on CoreValve devices and other CT-derived predictors is limited and reported results are discrepant. The value of aortic annulus eccentricity was investigated in only one small study [10] and aortic annulus size or the "cover index" was only analyzed in two relatively small 
CoreValve studies with conflicting results $[10,11]$. One of the reasons for these discrepancies may be the different methods of defining the PVL end-point: by angiography [10] versus pre-discharge transthoracic echocardiography [11]. Also, echocardiographic assessment of PVL was not performed according to the recently updated Valve Academic Research Consortium (VARC-2) criteria [12]. The current study sought to assess, in the thus far largest published single-center consecutive CoreValve series, the univariate and multivariate predictive value of CT-derived Agatston score, aortic annulus size and eccentricity, and "cover index" for significant PVL. PVL was defined according to both echocardiographic VARC-2 criteria (also for the first time defined as a continuous variable rather than a categorical variable) and angiographic Sellers criteria.

\section{Methods}

\section{Patients}

The study included 164 consecutive patients with severe aortic stenosis that underwent TAVI with a Medtronic CoreValve system $\odot$ from June 2006 to November 2012, with available pre-operative Agatston score and pre-discharge transthoracic echocardiography. The details of the TAVI implantation procedure are described in full detail elsewhere [13-15]. The first five patients underwent TAVI with the second-generation Medtronic CoreValve delivery system, which is implanted using a $21 \mathrm{Fr}$ catheter inserted into the common femoral $(n=4)$ or the subclavian $(\mathrm{n}=1)$ artery using surgical exposure without the use of an arterial sheath. All other patients underwent TAVI with the third-generation delivery system, using an $18 \mathrm{Fr}$ arterial sheath inserted into the femoral artery using an echocardiographic-guided Seldinger technique and closure with a 10Fr Prostar7 (Prostar XL, Abbott Vascular, IL); except for four who underwent the subclavian approach. All patients underwent general anesthesia, and valve implantation was done using cine and fluoroscopic guidance. The institutional review board approved the study.

\section{CT study}

A pre-operative CT scan was performed in all patients using dual source CT (Somatom Definition, Siemens Medical Solutions, Forchheim, Germany). A non-contrast calcification score acquisition was performed before contrast MSCT. The pitch was adjusted to fit the heart rate, and the volume of iodinated contrast material was adapted to the expected scan time: $50-60 \mathrm{ml}$ of VisipaqueVR $320 \mathrm{mg} \mathrm{1/ml}$, (GE Health Care, Eindhoven, The
Netherlands) were injected in an antecubital vein at a flow rate of $5.0 \mathrm{ml} / \mathrm{s}$ followed by a second contrast bolus of $30-40$ at $3.0 \mathrm{ml} / \mathrm{s}$. The scan ranged from the top of the aortic arch to the diaphragm. 3D reconstructions in end systole were obtained using a single-segmental algorithm with slice thickness $1.5 \mathrm{~mm}$ and increment $0.4 \mathrm{~mm}$. The radiation doses ranged from 8 to $20 \mathrm{mSv}$ depending on body habitus and table speed. The aortic annulus was defined as a virtual ring with three anchor points at the bases of the three aortic leaflets [16]; the minimum and maximum diameters and area of the annulus were measured in a viewing plane axial to the aortic root to match that definition [17]. Propriety software was developed to allow measurement of aortic annulus size on a contrast MSCT (3mensio Medical Imaging, Bilthoven, the Netherlands). A scan without contrast enhancement was available in 98 of 110 patients because it was initially not performed in patients with previous CABG or coronary stents. The non-contrast MSCT acquisition was performed in a prospectively ECG-triggered, sequential (step-and-shoot) mode with a reference tube current of $80 \mathrm{mAs}$, a tube voltage of $120 \mathrm{kV}$ and slice thickness of $3 \mathrm{~mm}$ in the early or mid diastolic heart phase depending on the heart rate; the latter data sets were used to derive the Agatstone score [18]. For analysis on a dedicated cardiovascular CT workstation (MMWP, Siemens AG, Forchheim, Germany) the aortic root was defined as the stretching from the caudal aspect of the aortic annulus to the origin of the left main stem as seen on axial images [19]. The threshold for the detection of calcium was set at $130 \mathrm{HU}$. In cases where aortic root cal-cification was confluent with calcium in adjacent structures (mitral annulus, ascending aorta, coronary arteries) only the stack of images that contained the aortic root were selected.

\section{Angiographic evaluation of paravalvular leakage}

Ten minutes after the deployment of the prosthetic valve, angiography of the aortic root was performed to assess the severity of aortic regurgitation according to Sellers criteria [20]. During evaluation of the aortography images the cases were labeled according to the following criteria: (0) no regurgitation; (1) only trace of contrast could be seen in the left ventricle, and it is cleared in each systole; (2) contrast filling the entire LV in diastole with less density compared with opacification of the ascending aorta; (3) contrast filling the entire LV in diastole equal in density to the contrast opacification of the ascending aorta; and (4) contrast filling of the entire LV in diastole on the first beat with greater density compared with the contrast opacification of the ascending aorta. Two observers independently scored the images. In case of discrepancy the images were re-evaluated and consensus was reached by a third observer. 


\section{Echocardiographic study}

All patients were evaluated after TAVI by pre-discharge transthoracic echocardiography using an iE33 ultrasound system (Philips Medical System, Best, the Netherlands) equipped with a S5-1 transducer. The extent of PVL was assessed according to the main VARC criterion, that is the circumferential extent of PVL in a parasternal short-axis view [12], as seen in Fig. 3. The VARC scores were provided as continuous values as well as categorical values: (0) no regurgitation; (1) mild PVL was defined as $<10 \%$ circumferential extent; (2) moderate PVL was defined as $>10 \%$ but $<30 \%$ of PVL and (3) severe PVL was defined as $>30 \%$ according to the updated VARC guideline [12]. Significant PVL was defined as a VARC-2 score more than mild.

\section{Predictors of PVL}

Maximal aortic annulus diameter [3] was obtained from the CT scans using three-dimensional reconstruction performed with the Siemens Circulation $\odot$ software, in a plane aligned to cut the lower part of all three the aortic cusps, as described earlier by us [11]. The Cover Index was defined as $100 \times$ (nominal prosthesis diameter - CT mean annulus diameter)/nominal prosthesis diameter [21, 22], and the Eccentricity Index was calculated as $100 \times(1-$ (aortic annulus minimum diameter / maximum diameter $)$ ) [10]. The annulus measurements for the latter indices were derived from the same CT plane described before, and the mean diameter was calculated as an average between the maximum and minimum one. The prosthesis nominal diameters used were provided by the manufacturer. The amount of calcification [7-9] was assessed as the Agatston score by the same CT analysis software in the non-contrast scans, with the interest zone confined to the segment of the aorta ranging from the anterior mitral leaflet to the origin of the left coronary artery.

\section{Statistical analysis}

All data gathered were analyzed using SPSS (IBM, version 20). Continuous variables were checked for normal distribution via the Kolmogorov-Smirnov test and were expressed as mean ( \pm standard deviation), median (25-75\% percentile), or number (percentage) as appropriate. Inter and intraobserver variability was expressed as correlation as well as weighted kappa for categories. The predictors were plotted against both the continuous values of VARC-2 score and the Sellers degree using Spearman correlation; $p$ values and Spearman's coefficient $(\rho)$ are provided. Because of a lack of homogeneity between the VARC-2 score, divided in four categories, and the Sellers' one, that recognizes five categories, the latter was compared with the continuous values of circumferential extent of the PVL. Each predictor was also tested against significant (more than mild) paravalvular regurgitation by Mann-Whitney test. Multivariate analysis was carried on by linear regression with a stepwise backward method.

\section{Results}

\section{Clinical and demographic characteristics of the population}

Of the 164 patients, 87 were male (54\%), and the median age was 81 (78-85) years. Pre-operative aortic mean pressure gradient was $43 \pm 15 \mathrm{~mm} \mathrm{Hg}$, and aortic valve area was $0.7 \pm 0.2 \mathrm{~cm}^{2}$. (Table 1) The Logistic Euroscore median was 13 (10-21). A $26 \mathrm{~mm}$ device was implanted in $42(26 \%)$ patients, a $29 \mathrm{~mm}$ in $113(69 \%)$ and a $31 \mathrm{~mm}$ in $9(5 \%)$ cases.

\section{Inter and intraobserver variability in the angiographic and echocardiographic evaluation}

Inter and intraobserver variability in the echocardiographic evaluation was assessed in a subset of 50 random patients. The same clips were evaluated by two experienced echocardiographers to provide an esteem of the interobserver variability $(r=0,92, p<0,05$ for continuous values) and were then re-evaluated in random order after some

Table 1 Clinical characteristics of the study population

\begin{tabular}{ll}
\hline Feature & Value \\
\hline Age (years), median (IQR) & $81(78-85)$ \\
Male, n (\%) & $87(54)$ \\
New York Heart Association class $\geq \mathrm{III}, \mathrm{n}(\%)$ & $132(81)$ \\
Previous cerebrovascular event, n (\%) & $39(24)$ \\
Previous myocardial infarction, n (\%) & $39(24)$ \\
Previous coronary artery bypass graft surgery, n (\%) & $49(30)$ \\
Previous percutaneous coronary intervention, n (\%) & $44(27)$ \\
Diabetes mellitus, n (\%) & $43(27)$ \\
Hypertension, n (\%) & $98(60)$ \\
Peripheral vascular disease, n (\%) & $19(12)$ \\
Chronic obstructive pulmonary disease, n (\%) & $43(27)$ \\
Laboratory results & \\
Creatinine (umol/l), median (IQR) & $93(74-118)$ \\
Haemoglobin (g/dl), median (IQR) & $7.7(7.1-8.4)$ \\
Logistic euroscore, median (IQR) & $13(10-21)$ \\
Mean aortic pressure gradient (mmHg), mean $\pm \mathrm{SD}$ & $43 \pm 15$ \\
Aortic valve area (cm ${ }^{2}$ ), mean $\pm \mathrm{SD}$ & $0.7 \pm 0.2$ \\
\hline
\end{tabular}


months by one of them to assess intraobserver variability $(\mathrm{r}=0,95, p<0,05)$. Categorical values were also not statistically different in interobserver variability (weighted $\kappa=0.86$; see Table 2).

Correlation in the Sellers' score series between the first and the second observer was acceptable $(r=0,87$, $p<0.05$ ); cathegorical values are provided for the same subset of patients selected for the previous analysis (weighted $\kappa=0.90$, see Table 3). To provide a better evaluation, however, a consensus was obtained from a third observer in case of disagreement and the resulting scores were used for further statistical analysis.

\section{Correlation between echocardiographic and angiographic evaluation of PVL}

At echocardiography PVL was not observed in 67 patients (41\%); it was mild in $44(27 \%)$, moderate in $44(27 \%)$, and severe in $9(5 \%)$. More than mild PVL was thus detected in 53 cases $(32 \%)$. The median values (25-75 percentiles) in the categories were $4 \%$ (3-8\%) for mild, $16 \%(12-21 \%)$ for moderate and $45 \%$ (33-50\%) for severe PVL (Fig. 1). Following Sellers criteria, the patients

Table 2 Category correlation for interobserver variability in VARC score in a subset of 50 random patients: weighted $\kappa=0.86$ $(0.66-0.93)$

\begin{tabular}{lrrrrr}
\hline Observer 1 & \multicolumn{1}{l}{} & & & \\
\hline Grade & 0 & +1 & +2 & +3 & Total \\
\hline Observer 2 & & & & & \\
0 & 19 & 1 & 0 & 0 & 20 \\
+1 & 0 & 12 & 2 & 0 & 14 \\
+2 & 0 & 2 & 11 & 1 & 14 \\
+3 & 0 & 0 & 1 & 1 & 2 \\
Total & 19 & 15 & 14 & 2 & 50 \\
\hline
\end{tabular}

$0=$ none, $1=$ mild, $2=$ moderate, $3=$ severe

Table 3 Category correlation for interobserver variability in Sellers' score in a subset of 50 random patients: weighted $\kappa=0.90$ $(0.74-0.99)$

\begin{tabular}{lllllll}
\hline Observer 1 & & & & & & \\
\hline Grade & 0 & +1 & +2 & +3 & +4 & Total
\end{tabular}

Observer 2

\begin{tabular}{rrrrrrr}
0 & 5 & 0 & 0 & 0 & 0 & 5 \\
+1 & 0 & 11 & 1 & 0 & 0 & 14 \\
+2 & 0 & 2 & 26 & 0 & 0 & 14 \\
+3 & 0 & 0 & 1 & 4 & 0 & 5 \\
+4 & 0 & 0 & 0 & 0 & 0 & 0 \\
Total & 5 & 13 & 28 & 4 & 0 & 50 \\
\hline
\end{tabular}

were classified as aortic regurgitation grade 0 in $12(7 \%)$ cases, grade 1 in 39 (24\%), grade 2 in 99 (60\%), and grade 3 in 14 (9\%). No patient had grade 4 aortic regurgitation. There was a significant correlation between the Sellers and VARC score $(\rho=0.481, p<0.001)$ (Fig. 2).

\section{Correlation between aortic annulus and cover index}

There was a significant inverse correlation $(\rho=-0.734$, $p<0.001)$ between the maximum aortic annulus diameter and the cover index.

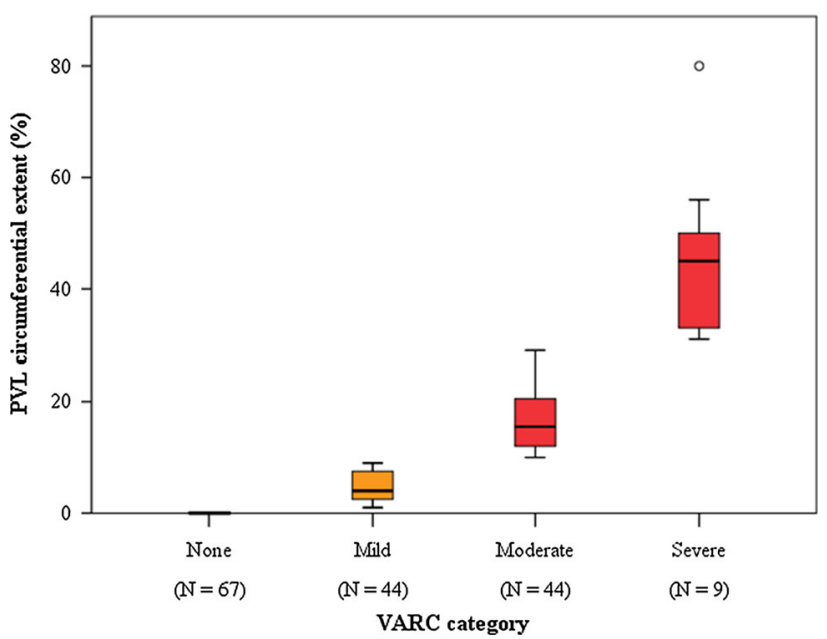

Fig. 1 Distribution of VARC-2 scores according to the VARC-2 categories

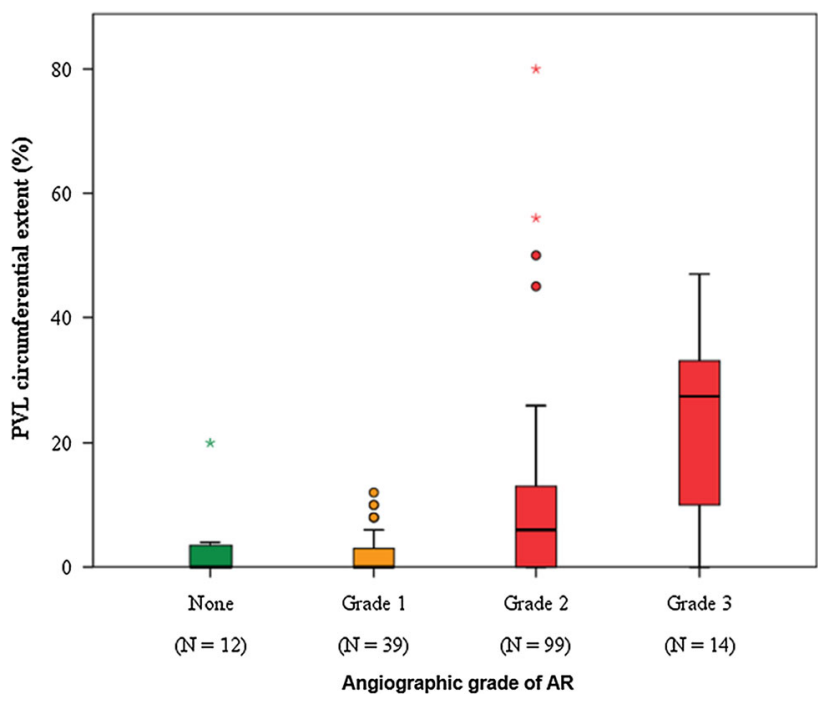

Fig. 2 Correlation between angiographic Sellers grading and continuous value of VARC-2 scores for the assessment of paravalvular leakage 


\section{Predictors of PVL as assessed by angiography (Sellers)}

As seen in Tables 4 and 5, significant predictors for more than mild PVL assessed by angiography were the maximal diameter of the aortic annulus size $(27.9 \pm 2.6$ vs. $26.7 \pm 2.3 \mathrm{~mm}, p=0.006$; correlation $0.178, p=$ $0.005)$, cover index (12.6 [9.6-15.1] vs. 14.4 [11.8-18.2], $p=0.007$; correlation $-0.143, p=0.019]$ ), and Agatston score $(3,346[2,363-4886]$ vs. 2123 [1477-2777] Hounsfield units, $p<0.001$; correlation $0.395, p<$ $0.001)$. The eccentricity index was not a predictor for PVL.

\section{Predictors of PVL as assessed by echocardiography (VARC-2)}

As seen in Tables 4 and 5, significant predictors for more than mild PVL assessed by echocardiography were the maximal diameter of the aortic annulus size $(28.1 \pm$ 2.4 vs. $27.2 \pm 2.5 \mathrm{~mm}, p=0.039$; correlation 0.210 , $p=0.003$ ), and Agatston score (3952 [2528-5071] vs. 2596 [1782-4034] Hounsfield units, $p=0.001$; correlation $0.305, p<0.001)$. Although not a significant predictor, a weak but significant correlation existed between the cover index and PVL (correlation -0.134, $p=0.043)$. The eccentricity index was not a predictor for PVL.

\section{Multivariate analysis}

At multivariate analysis, the Agatston score was the only independent predictor for PVL, regardless of the method of PVL assessment: $p=0.001, \beta=0.265$ for the echocardiographic VARC score and $p=0.004, \beta=0.272$ for the angiographic Sellers score (Fig. 3).

\section{Discussion}

The main findings of this study are: (1) maximal aortic annulus diameter and Agatston score predicted more than mild PVL and correlated to PVL extent regardless of the used imaging technique to define PVL, (2) cover index predicted angiographic PVL but did not predict echocardiographic PVL, although a weak but significant correlation existed, (3) aortic annulus eccentricity did not predict PVL, and (4) Agatston score was for both PVL imaging techniques the only independent predictor for PVL.

The literature about prediction of PVL after implantation of a CoreValve prosthesis is limited because of the relatively small number of available CoreValve specific reports $[7,8,10,11,23,24]$, including small number of patients, conflicting results, assessment of PVL by different techniques (angiography [10] versus pre-discharge transthoracic echocardiography [11]), and the use of echocardiographic methods not recommended by the VARC [3, 25]. The present study is the largest so far

Table 4 Prediction of aortic paravalvular leakage as assessed by echocardiography (VARC-2) and angiography (Sellers)

\begin{tabular}{|c|c|c|c|c|c|c|}
\hline \multirow[t]{2}{*}{ Predictor } & \multicolumn{3}{|c|}{ Echocardiographic VARC-2 score } & \multicolumn{3}{|c|}{ Angiographic Sellers score } \\
\hline & $\begin{array}{l}\text { None or mild } \\
\mathrm{n}=111\end{array}$ & $\begin{array}{l}\text { More than mild } \\
\mathrm{n}=53\end{array}$ & $p$ value & $\begin{array}{l}\text { None or mild } \\
\mathrm{n}=51\end{array}$ & $\begin{array}{l}\text { More than mild } \\
\mathrm{n}=113\end{array}$ & $p$ value \\
\hline $\begin{array}{l}\text { Maximal annulus diameter, } \\
\mathrm{mm}\end{array}$ & $27.2 \pm 2.5$ & $28.1 \pm 2.4$ & 0.039 & $26.7 \pm 2.3$ & $27.9 \pm 2.6$ & 0.006 \\
\hline Cover index $(\%)$ & $14.0(10.3-17.3)$ & $12.6(8.6-16.4)$ & 0.204 & $14.4(11.8-18.2)$ & $12.6(9.6-15.1)$ & 0.007 \\
\hline Eccentricity index $(\%)$ & $20.4 \pm 6.7$ & $20.9 \pm 6.4$ & 0.644 & $20.5 \pm 6.4$ & $20.6 \pm 6.7$ & 0.939 \\
\hline Agatston score & $2596(1782-4034)$ & $3952(2528-5071)$ & 0.001 & $2123(1477-2777)$ & $3346(2363-4886)$ & $<0.001$ \\
\hline
\end{tabular}

Table 5 Correlations between predictors for aortic paravalvular leakage and actual paravalvular leakage as assessed by echocardiography (VARC-2) and angiography (Sellers)

\begin{tabular}{|c|c|c|c|c|}
\hline \multirow[t]{2}{*}{ Predictor } & \multicolumn{2}{|c|}{ VARC-2 score } & \multicolumn{2}{|c|}{ Angiography score } \\
\hline & $\rho$ value & $p$ value & $\rho$ value & $p$ value \\
\hline Maximal annulus diameter & 0.210 & 0.003 & 0.178 & 0.005 \\
\hline Cover index & -0.134 & 0.043 & -0.143 & 0.019 \\
\hline Eccentricity index & 0.030 & 0.350 & 0.036 & 0.303 \\
\hline Agatston score & 0.305 & $<0.001$ & 0.395 & $<0.001$ \\
\hline
\end{tabular}


Fig. 3 Examples from two patients with low and high Agatston score, respectively and corresponding colour Doppler short-axis views of paravalvular leak on $2 \mathrm{D}$ echocardiography
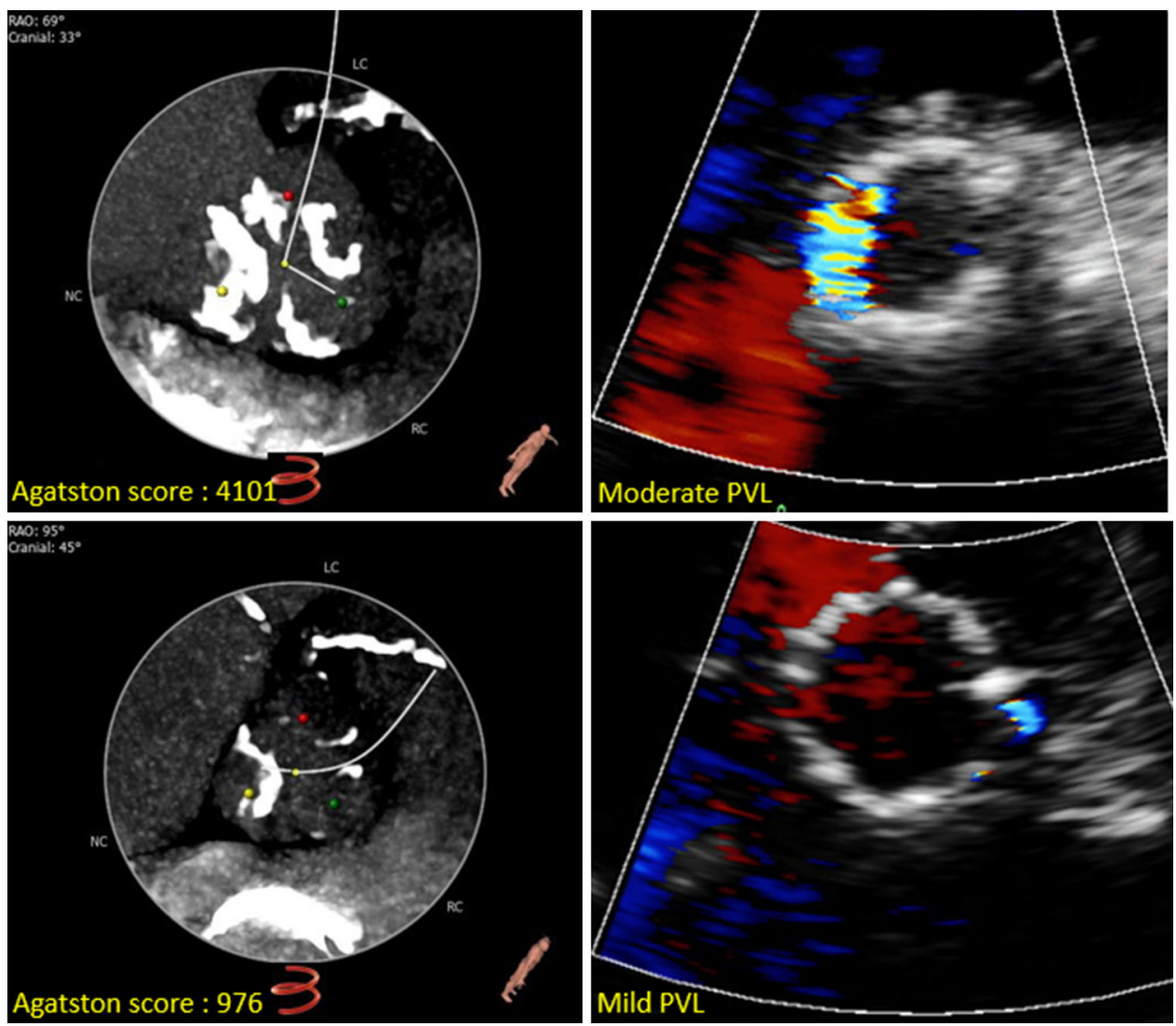

published single-center consecutive CoreValve series describing prediction of PVL as defined by both angiographic and VARC echocardiography criteria with wellknown parameters as the Agatston score, aortic annulus size and eccentricity, and the cover index. Also, correlations between predictors and outcome (PVL) parameters were for the first time based on both continuous variables and categorical variables.

Aortic annulus calcification measured by Agatston score was predictive for PVL in all published CoreValve specific studies [7, 8, 11] and in our study it was the only independent predictor of PVL, regardless of its definition by angiography or echocardiography. The relationship between aortic annulus calcification and the incidence of PVL is based on a suboptimal adherence of the prosthesis to the aortic root walls because of the calcified native leaflets that, even if crushed by balloon inflation before, during, or after the procedure, cannot be totally removed. The powerful Agatston score was recently reported to even predict cardiovascular events [7].

In addition, lower values of the cover index were correlated with the severity of PVL, confirming that a prosthesis that is too small related to the native annulus can induce PVL. This has already led to a tendency to oversize the prosthesis [26]. The relationship between the larger size of the aortic annulus and the incidence of PVL is probably due to a greater probability of undersizing of the prosthetic valve; patients with a larger aortic annulus had indeed lower cover index values. It should also be noted that only at the final time frame of this study the largest $(31 \mathrm{~mm})$ CoreValve prosthesis size became available. Although not an independent predictor for PVL it should be recognised that the cover index is in fact the only one on which the interventional cardiologist can actually intervene, since all others are strictly related to the anatomy of the patient.

The aortic annulus is well known to be eccentric [27] but the eccentricity index did not predict PVL. Its value recently already met some criticism [28]. It is known that, according to CT scans before and after TAVI with balloonexpandable devices, the aortic annulus becomes more circular after the prosthesis placement, adapting to its shape $[22,29,30]$. Therefore, it may be expected that the annular shape may influence the grade of PVL only to a small extent. However, the CoreValve prosthesis is self-expandable and may adapt more to the annulus rather than vice versa. Our data show that also with the CoreValve prosthesis aortic annulus eccentricity does not influence the grade of PVL, although it cannot be excluded that balloon inflation performed before the implantation in patients with a significant calcium burden may have influenced this result. 


\section{Limitations}

The Sellers score includes total aortic regurgitation (transvalvular and paravalvular cannot be separately assessed) which will always to some extent limit the correlation to an echocardiographic PVL score. However, transvalvular aortic regurgitation was seen on echocardiography in a very small amount of patients and was usually trivial.

Both the Sellers score and the VARC score are highly subjective. In particular, the echocardiographic VARC one is not validated and harbours many difficulties such as underestimation due to poor acoustic windows or an incorrect (to high) level of image acquisition, or overestimation due to circumferentially flying jets and an incorrect (to low) level of image acquisition.

\section{Conclusion}

The Agatston score is the only independent predictor of PVL regardless of the used imaging technique for the definition of PVL.

\section{Complaince with Ethical Standards}

Conflict of interest The authors declare that they have no conflict of interest.

Open Access This article is distributed under the terms of the Creative Commons Attribution 4.0 International License (http://crea tivecommons.org/licenses/by/4.0/), which permits unrestricted use, distribution, and reproduction in any medium, provided you give appropriate credit to the original author(s) and the source, provide a link to the Creative Commons license, and indicate if changes were made.

\section{References}

1. Kodali SK, Williams MR, Smith CR et al (2012) Two-year outcomes after transcatheter or surgical aortic-valve replacement. N Engl J Med 366:1686-1695. doi:10.1056/NEJMoa1200384

2. Wenaweser P, Stortecky S, Schwander S et al (2013) Clinical outcomes of patients with estimated low or intermediate surgical risk undergoing transcatheter aortic valve implantation. Eur Heart J 34:1894-1905. doi:10.1093/eurheartj/eht086

3. Athappan G, Patvardhan E, Tuzcu EM et al (2013) Incidence, predictors, and outcomes of aortic regurgitation after transcatheter aortic valve replacement. J Am Coll Cardiol 61:1585-1595. doi:10.1016/j.jacc.2013.01.047

4. Gotzmann M, Lindstaedt M, Mügge A (2012) From pressure overload to volume overload: aortic regurgitation after transcatheter aortic valve implantation. Am Heart J 163:903-911. doi:10.1016/j.ahj.2012.03.017

5. Généreux P, Head SJ, Hahn R et al (2013) Paravalvular leak after transcatheter aortic valve replacementthe new Achilles' heel? A comprehensive review of the literature. J Am Coll Cardiol 61:1125-1136. doi:10.1016/j.jacc.2012.08.1039
6. Abdel-Wahab M, Zahn R, Gerckens U et al (2014) Predictors of 1 -year mortality in patients with aortic regurgitation after transcatheter aortic valve implantation: an analysis from the multicentre German TAVI registry. Heart $\mathrm{Br}$ Card Soc 100:1250-1256. doi:10.1136/heartjnl-2013-305385

7. Leber AW, Kasel M, Ischinger T et al (2013) Aortic valve calcium score as a predictor for outcome after TAVI using the CoreValve revalving system. Int J Cardiol 166:652-657. doi:10. 1016/j.ijcard.2011.11.091

8. John D, Buellesfeld L, Yuecel S et al (2010) Correlation of device landing zone calcification and acute procedural success in patients undergoing transcatheter aortic valve implantations with the self-expanding CoreValve prosthesis. JACC Cardiovasc Interv 3:233-243. doi:10.1016/j.jcin.2009.11.015

9. Staubach S, Franke J, Gerckens U et al (2013) Impact of aortic valve calcification on the outcome of transcatheter aortic valve implantation: results from the prospective multicenter German TAVI registry. Catheter Cardiovasc Interv 81:348-355. doi:10. $1002 /$ ccd. 24332

10. Wong DTL, Bertaso AG, Liew GYH et al (2013) Relationship of aortic annular eccentricity and paravalvular regurgitation post transcatheter aortic valve implantation with CoreValve. J Invasive Cardiol 25:190-195

11. Schultz CJ, Tzikas A, Moelker A et al (2011) Correlates on MSCT of paravalvular aortic regurgitation after transcatheter aortic valve implantation using the medtronic corevalve prosthesis. Catheter Cardiovasc Interv. doi:10.1002/ccd.22993

12. Kappetein AP, Head SJ, Généreux P et al (2013) Updated standardized endpoint definitions for transcatheter aortic valve implantation: the Valve Academic Research Consortium-2 consensus document. J Thorac Cardiovasc Surg 145:6-23. doi:10. 1016/j.jtcvs.2012.09.002

13. Nuis R-J, van Mieghem NM, van der Boon RM et al (2011) Effect of experience on results of transcatheter aortic valve implantation using a Medtronic CoreValve System. Am J Cardiol 107:1824-1829. doi:10.1016/j.amjcard.2011.02.315

14. Nuis R-J, Van Mieghem NM, Schultz CJ et al (2012) Frequency and causes of stroke during or after transcatheter aortic valve implantation. Am J Cardiol 109:1637-1643. doi:10.1016/j.amj card.2012.01.389

15. Webb JG, Chandavimol M, Thompson CR et al (2006) Percutaneous aortic valve implantation retrograde from the femoral artery. Circulation 113:842-850. doi:10.1161/CIRCULATIO NAHA. 105.582882

16. Piazza N, de Jaegere P, Schultz C et al (2008) Anatomy of the aortic valvar complex and its implications for transcatheter implantation of the aortic valve. Circ Cardiovasc Interv 1:74-81. doi:10.1161/CIRCINTERVENTIONS.108.780858

17. Schultz C, Moelker A, Tzikas A et al (2010) The use of MSCT for the evaluation of the aortic root before transcutaneous aortic valve implantation: the Rotterdam approach. EuroInterv J Eur Collab Work Group Interv Cardiol Eur Soc Cardiol 6:505-511. doi:10.4244/EIJ30V6I4A84

18. Agatston AS, Janowitz WR, Hildner FJ et al (1990) Quantification of coronary artery calcium using ultrafast computed tomography. J Am Coll Cardiol 15:827-832

19. Messika-Zeitoun D, Aubry M-C, Detaint D et al (2004) Evaluation and clinical implications of aortic valve calcification measured by electron-beam computed tomography. Circulation 110:356-362. doi:10.1161/01.CIR.0000135469.82545.D0

20. Sellers R, Levy M, Amplatz K, Lillehei C (1964) Left retrograde cardioangiography in acquired cardiac disease: technic, indications and interpretations in 700 cases. Am J Cardiol 14:437-447

21. Détaint D, Lepage L, Himbert D et al (2009) Determinants of significant paravalvular regurgitation after transcatheter aortic 
valve implantation. JACC Cardiovasc Interv 2:821-827. doi:10. 1016/j.jcin.2009.07.003

22. Willson AB, Webb JG, LaBounty TM et al (2012) 3-dimensional aortic annular assessment by multidetector computed tomography predicts moderate or severe paravalvular regurgitation after transcatheter aortic valve replacement. J Am Coll Cardiol 59:1287-1294. doi:10.1016/j.jacc.2011.12.015

23. Schultz C, Rossi A, van Mieghem N et al (2011) Aortic annulus dimensions and leaflet calcification from contrast MSCT predict the need for balloon post-dilatation after TAVI with the Medtronic CoreValve prosthesis. EuroInterv J Eur Collab Work Group Interv Cardiol Eur Soc Cardiol 7:564-572. doi:10.4244/ EIJV7I5A92

24. Takagi K, Latib A, Al-Lamee R et al (2011) Predictors of moderate-to-severe paravalvular aortic regurgitation immediately after corevalve implantation and the impact of postdilatation. Catheter Cardiovasc Interv. doi: $10.1002 / \mathrm{ccd} .23003$

25. Lerakis S, Hayek SS, Douglas PS (2013) Paravalvular aortic leak after transcatheter aortic valve replacement: current knowledge. Circulation 127:397-407. doi:10.1161/CIRCULATIONAHA. 112.142000

26. Samim M, Stella PR, Agostoni P et al (2013) A prospective "oversizing" strategy of the Edwards SAPIEN bioprosthesis: results and impact on aortic regurgitation. J Thorac Cardiovasc Surg 145:398-405. doi:10.1016/j.jtcvs.2011.12.067

27. Tops LF, Wood DA, Delgado V et al (2008) Noninvasive evaluation of the aortic root with multislice computed tomography implications for transcatheter aortic valve replacement. JACC Cardiovasc Imaging 1:321-330. doi:10.1016/j.jcmg.2007.12.006

28. Jabbour A, Ismail TF, Moat $\mathrm{N}$ et al (2011) Multimodality imaging in transcatheter aortic valve implantation and post-procedural aortic regurgitation. J Am Coll Cardiol 58:2165-2173. doi:10.1016/j.jacc.2011.09.010

29. Wood DA, Tops LF, Mayo JR et al (2009) Role of multislice computed tomography in transcatheter aortic valve replacement. Am J Cardiol 103:1295-1301. doi:10.1016/j.amjcard.2009.01. 034

30. Delgado V, Ng ACT, van de Veire NR et al (2010) Transcatheter aortic valve implantation: role of multi-detector row computed tomography to evaluate prosthesis positioning and deployment in relation to valve function. Eur Heart $\mathrm{J}$ 31:1114-1123. doi:10. 1093/eurheartj/ehq018 